\title{
Profesor Dr. Héctor F. Girardi
}

\author{
Celebración de vida
}

A gradecemos la oportunidad brindada por la Asociación Argentina de Ortopedia y Traumatología para celebrar la vida de nuestro amado Padre quien fue Presidente de dicha Asociación en el año 2000.

Nuestro padre nació en la localidad de María Susana, Provincia de Santa

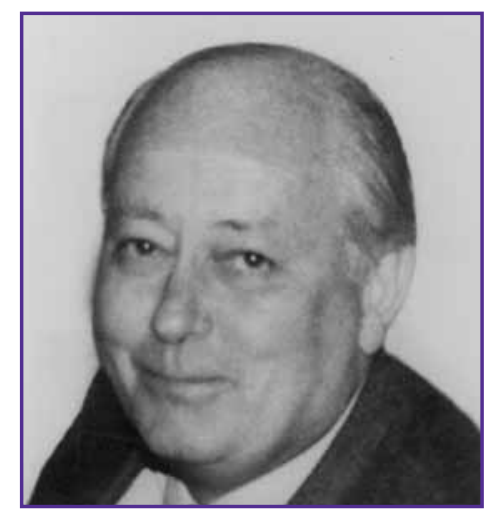
Fe en el año 1934. Estudió la secundaria y Facultad en la ciudad de Rosario. Se casó en primeras nupcias con la mujer que amó, madre de sus cuatro hijos, que solo los separó la muerte. Se recibió de médico en el año 1960 en la Universidad de Rosario y desarrolló su especialidad de Ortopedia y Traumatología bajo la mentoría de grandes rosarinos, como los Doctores Marottoli, Celoria y Didier (todos ex Presidentes de la AAOT).

Durante su carrera asistencial pública llegó a ser Jefe de los Servicios de la Asistencia Pública (Ex Hospital de Emergencias), Hospital de Niños "José Vilela", y Hospital Provincial de Rosario. Creó la Unidad Docente en este último Hospital dependiente de la Universidad de Nacional de Rosario de la que fue Director hasta su Jubilación. También fue Director del Hospital Provincial durante varios años.

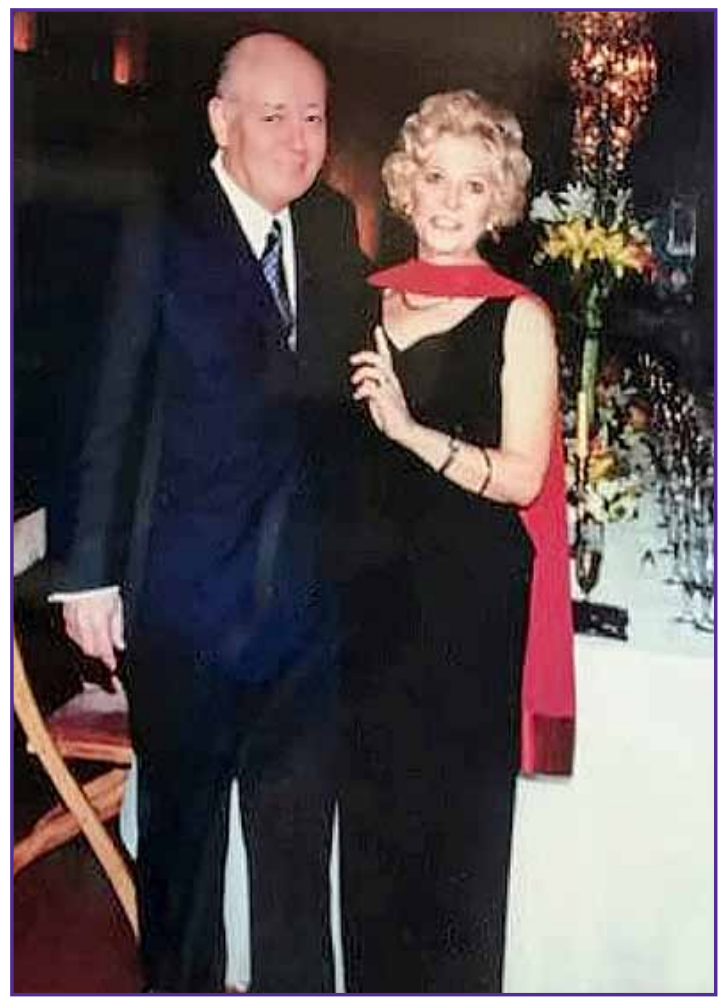

En cuanto a lo académico, fue Profesor adjunto encargado de la cátedra de Ortopedia en el Hospital Provincial desde su creación hasta su jubilación, fue Presidente de la Sociedad de Ortopedia del Litoral, Sociedad de Trabajo de Rosario y como dicho antes, de la AAOT, Asociación que amaba y admiraba desde joven. Dirigió el curso anual de la AAOT en Rosario por años. Con orgullo y una dedicación admirable viajaba en colectivo por el día para asistir a las reuniones. En el año 2001 fue el Presidente del Congreso de la AAOT, con una altísima participación no solo de asistentes, sino de invitados extranjeros, fundamentalmente del prestigioso Hospital for Special Surgery. Esto no fue fácil ya que fue tan solo tres meses después del atentado más grave en suelo americano.

En lo privado fue Jefe del Servicio de PASA Petroquímica, y Presidente y Jefe del Servicio del Sanatorio Americano en la ciudad.

Nuestro padre fue un gran participante de la sociedad rosarina, siendo miembro de clubes de larga trayectoria, como el Jockey Club, Rotary Club, etc. Fue Presidente de la Sociedad de Beneficencia del Hospital Provincial y Presidente del Banco de elementos Ortopédicos del Rotary Club, entidades que han hecho mucho bien a los más necesitados en la ciudad. Fue candidato a la Intendencia en Rosario en la gloriosa vuelta de la democracia.

Dr. HÉCTOR F. GIRARDI (h) • hectorgirardi@gmail.com

ittps://orcid.org/0000-0002-2886-309x

Cómo citar este artículo: Girardi FP, Girardi HF. Obituario. Profesor Dr. Héctor F. Girardi. Celebración de vida. Rev Asoc Argent Ortop Traumato/ 2021;86(1):133-134. https://doi.org/10.15417/ issn. 1852-7434.2021.86.1.1292 
Para nosotros, más del orgullo profesional que nos has dado, papá fue el mejor padre que uno puede aspirar. La gente lo describía como caballero, honesto, justo, hombre de bien, excelente marido, padre, hijo, abuelo, hermano y amigo. Entre muchas otras cosas. Dos de sus cuatro hijos seguimos su especialidad ya que fue fácil enamorarse de ella, viendo su dedicación, humildad y formación inagotable.

Él siempre nos decía que la práctica médica debe reunir investigación, clínica y docencia. Desde ya que él lo hizo incondicionalmente.

Más allá de la tristeza que nos causó su partida física, celebramos día a día su vida y ojalá podamos imitarlo el resto de nuestras vidas.

Nos ha dejado un legado digno de admirar y seguir sus pasos.

Agradecidos por siempre, te llevamos en nuestros corazones.

Federico P. Girardi, MD

Profesor de Cirugía Ortopédica

Weill Medicine of Cornell University

Attending Surgeon

Hospital for Special Surgery

Nueva York, NY, EE.UU.

Dr. Héctor F. Girardi (h)

Jefe del Servicio de Ortopedia y Traumatología

Sanatorio Americano

Rosario, Argentina 